\title{
Modern Intellectual Property Governance and Openness in Europe: A Long and Winding Road?
}

\author{
Nikos Koutras
}

\section{Abstract}

In the last decade a trend towards more 'openness' in terms of collaborations and access to knowledge has been observed in many different sectors and contexts. Along the spectrum of openness one can find many different varieties, such as open innovation, co-creation, open science (combined with open access and open data) and open source. Even traditionally rather 'closed' actors, such as publishing houses and the pharmaceutical industry, are gradually catching up and are trying to develop mechanisms to cope with this trend towards openness. Both public and private actors encounter challenges in combining this trend towards openness with the management of intellectual property rights (IPRs). Although a strong willingness may exist to collaborate, open up and share knowledge and data, IPRs often create boundaries and limitations towards cuttingedge collaborations and initiatives for openness and sharing. Over time, companies, universities, public research organisations, etc. have developed certain models to allow for openness while safeguarding ways to protect their IPRs. Yet the legal framework is often lagging behind and does not appear to reflect the socio-economic trend towards openness; in many jurisdictions, changes to IP legislation have rather focused on strengthening of the rights of IP owners. But this is not necessarily a problem as stakeholders tend to find workarounds in their day-to-day practice. This special issue aims to further the discussion about modern governance of IPRs in Europe and to explore different perspectives on how openness could be operationalised within the context of IP protection.

\section{Overview of the Special Issue}

In the last decade a trend towards more 'openness' in terms of collaborations and access to knowledge has been observed in many different sectors and contexts. Along the spectrum of openness one can find many different varieties, such as open innovation, co-creation, open science (combined with open access and open data) and open source. Even traditionally rather 'closed' actors, such as publishing houses and the pharmaceutical industry, are gradually catching up and are trying to develop mechanisms to cope with this trend towards openness. Both public and private actors encounter challenges in combining this trend towards openness with the management of intellectual property rights (IPRs). Although a strong willingness may exist to collaborate, open up and share knowledge and data, IPRs often create boundaries and limitations towards cuttingedge collaborations and initiatives for openness and sharing. Over time, companies, universities, public research organisations, etc. have developed certain models to allow for openness while safeguarding ways to protect their IPRs. Yet the legal framework is often lagging behind and does not appear to reflect the socioeconomic trend towards openness; in many jurisdictions, changes to IP legislation have rather focused on strengthening of the rights of IP owners. But this is not necessarily a problem as stakeholders tend to find workarounds in their day-to-day practice. This special issue aims to further the discussion about modern governance of IPRs in Europe and to explore different perspectives on how openness could be operationalised within the context of IP protection.

\section{Structure of the Special Issue}

In this respect, it is necessary to trace the historical development of the concept of copyright as a property right. The continued relevance of the rationales for copyright interests, both philosophical and pragmatic, will be assessed against digital publishing in contemporary times. Furthermore, the special issue examines the rise of open access practice and includes an analysis of the impact of the online publishing and associated revolution on commercial publishing methods. In the first article, Nikos Koutras investigates the transition from property rights to copyrights, considers justifications based on which the concept of private property was introduced and analyses how the idea of private property in land and goods was extended to creative efforts. Additionally, Koutras argues that the concept of open access supports wider distribution of information resources. Therefore, in modern times, when information and communication technologies are undergoing a 'revolution', it is imperative to go back to Plato's concept and argue that open access is an instrument with benefits of wide dissemination of information resources. 
Hence, there is a need to connect the emergence of copyright protection with developments in the concept of property. The same connections can justify the development of open access in contemporary times; for instance, balancing individual rights with the social good.

Given this, intellectual efforts are produced and uploaded online with ease, nowadays. Therefore, additional issues arise in terms of online data produced and shared. In the second article, Alexandra Giannopoulou discusses data sharing. In particular, she argues that data sharing has been at the forefront of policy and legislative reforms in recent years, from open source software to open government data and from open research data to open science in general. The innovation potential that incites enhancing data access and reusability practices illustrates significant value derived from data sharing practices. Access to knowledge is considered not only a vector for scientific progress that stimulates innovation but also an indispensable tool committed to the development of a democratic society. The smart use of data has a transformative effect on the economy and on society in general.

Another field of research where an enormous amount of data is produced and disseminated, when required, is the field of medicine and its regulatory framework in terms of medical data, which has been covered in the special issue, where, in the third article, Magali Contardi argues that medical devices play an increasingly important role in healthcare worldwide by contributing substantially to the prevention, diagnosis and treatment of diseases. At the European level, enhancing competitiveness while ensuring public health and safety is one of the key objectives of the European Commission. In the pursuit of such objectives, medical devices within Europe have been regulated since 1990 by means of three directives, namely Directive 90/385/ECC concerning active implantable medical devices (AIMDD), Directive 93/42/ECC, concerning medical devices (MDD), and Directive $98 / 79 / \mathrm{ECC}$, concerning in vitro diagnostic medical devices (IVDD). Over the past few years, the system has been subject to amendments and has been complemented by several non-binding guidance documents reflecting the consensus of stakeholders.

In the fourth article, Maria Canellopoulou-Bottis, Marinos Papadopoulos, Christos Zampakolas and Vicky Ganatsiou argue that in the post-paper world, libraries implement Web-harvesting and Web-archiving methods in several countries facing technological and legal issues that are intensified owing to the idea of 'openness' regarding access to information or openness to partnerships. The core theme of this special issue could also be seen through the prism of the 'intellectual property and contemporary issues of openness' thematic. Web harvesting and Web archiving as a technological option is usually leveraged on in the context of legal deposit systems that are set in the legal and technical frameworks of operation of major and/or national libraries, and aim at the collection, download and archiving of works that are found available on the Internet through an automated process of tracking and pulling of works found online. In addition, Maria Canellopoulou-Bottis, Marinos Papadopoulos, Christos Zampakolas and Vicky Ganatsiou also consider that access to the Web information and works available online is subject to restrictions by regulation, especially laws pertaining to copyright, industrial property rights, data privacy, etc. on the same model as the current legal deposit material on hard copies in most libraries empowered to do the legal deposit.

The special issue also furthers the consideration in regard to Web harvesting and Web archiving. Thus, in the fifth article, Maria Canellopoulou-Bottis, Marinos Papadopoulos, Christos Zampakolas and Vicky Ganatsiou discuss the term Text and Data Mining (hereinafter, TDM). In fact, TDM determines an issue for the purpose of scientific research or for any other purpose that is included in the provisions of the new EU Directive on Copyright in the Digital Single Market (hereinafter, DSM). TDM includes Web-harvesting and Webarchiving activities. Web harvesting and archiving pertain to the processes of collecting from the Web and archiving of works that reside on the Web. Web harvesting and Web archiving are one of the most attractive applications for libraries that plan ahead for their future operation. When works retrieved from the Web are turned into archived and documented material to be found in a library, the volume of works that can be found in such libraries can far exceed the number of works harvested from the Web. The fifth article elaborates on provisions in EU Copyright law that were discussed during the proposal for a new Directive on Copyright in the DSM as well as provisions that are included in the text of art. 3 and art. 4 of the new Directive 2019/790/EU per TDM.

In conclusion, the special issue welcomes a more practical approach concerning intellectual property issues, which is shown in the sixth article, where Nikos Koutras investigates the interaction of public policy with the dissemination of scientific information. What is more, Koutras argues that public policy is crucial to simultaneously developing green open access as a form of social justice and social cohesion enhancement; in other words, as a tool to increase access opportunities. It is widely acknowledged that information access is imperative, while the current copyright regimes afford overly broad protection in terms of the duration, works and uses covered. Hence, the last article proposes a socioeconomic framework to develop a standard concerning the balance of stakeholder interests based on green open access via public policy. 